\title{
Preparation and characterization of chitosan extracted from shrimp shells waste and chitosan film: application for Eriochrome black T removal from aqueous solutions
}

\author{
Nacer Boudouaia ${ }^{1} \cdot$ Zohra Bengharez $^{1}$ (D) Salah Jellali ${ }^{2}$
}

Received: 19 November 2018 / Accepted: 5 May 2019 / Published online: 13 May 2019

(c) The Author(s) 2019

\begin{abstract}
In this paper, chitosan (CS) was successfully extracted from shrimp shells waste at two deacetylation temperatures $\left(90{ }^{\circ} \mathrm{C}\right.$ and $40^{\circ} \mathrm{C}$ ). The obtained chitosan at $90{ }^{\circ} \mathrm{C}$ showed better physicochemical properties compared to the one prepared at $40{ }^{\circ} \mathrm{C}$ with a degree of deacetylation $\mathrm{DA}=88 \%$, molecular weight $M=353 \mathrm{KDa}$, viscosity $\eta=0.469 \mathrm{dL} / \mathrm{g}$ and $\mathrm{pKa}=6.49$, and its structure was confirmed by Fourier transform infrared spectroscopy, X-ray diffraction and differential scanning calorimetry. The extracted CS was utilized as a film for the adsorption of Eriochrome black T (EBT) dye from aqueous solutions under various experimental conditions. Experimental results showed that the synthesized film exhibited excellent adsorption ability for EBT with an adsorption capacity of $413 \mathrm{mg} / \mathrm{g}$ at $\mathrm{pH} 4.66$ for an initial dye concentration of $200 \mathrm{mg} / \mathrm{L}$ at $20{ }^{\circ} \mathrm{C}$. The kinetics of adsorption were found to be of pseudo-second order with a high coefficient of determination $\left(R^{2}=0.9999\right)$. Furthermore, the thermodynamic analysis revealed that the adsorption of EBT dye was an endothermic and spontaneous process. Freundlich model fitted well to the experimental data, the numerical value of $n=1.064$ indicates that adsorption of EBT onto CS film is favorable. All these results confirm that chitosan-based films prepared from shrimp shells waste could be considered as promising materials for dye removal and as alternatives to expensive adsorbents.
\end{abstract}

Keywords Chitosan $\cdot$ Extraction · Deacetylation · Eriochrome black T · Adsorption study

\section{Introduction}

Dyes are considered as ones of the most worldwide employed chemicals. Under certain conditions, they could present a real menace to the environment in general and to water resources in particular through the establishment of the eutrophication process. During the last decades, various physicochemical techniques have been used for removal of dyes from industrial effluents such as coagulation/flocculation (Fosso-Kankeu et al. 2017), ozonation (Smita et al. 2017), electrochemical oxidation (Akrout et al. 2015). Adsorption onto low-cost materials has pointed out as one

Zohra Bengharez

dzbengharez@yahoo.fr

1 Laboratory of Advanced Materials and Physicochemistry for Environment and Health, Faculty of Exact Sciences, Djillali Liabes University, 22000 Sidi Bel Abbès, Algeria

2 Wastewaters and Environment Laboratory, Water Research and Technologies Center, Echopark of Borj Cedria, 8020 Soliman, Tunisia of the most effective methods for dye removal especially for low concentrated effluents (Bharathi and Ramesh 2013). Various materials have been successfully used for dye removal in static and/or dynamic mode such as orange tree sawdust (Azzaz et al. 2017), cellulose-based bioadsorbent (Liu et al. 2015), different marine macroalgae (Omar et al. 2018) and chitosan (Vega-Negron et al. 2018).

Shellfish shells are biowastes that could be responsible for pollution in coastal areas. However, these biowastes could be valorized and used as resources for the production of chitin and chitosan, through three-stage extraction, namely demineralization, deproteinization and deacetylation (Mohammed et al. 2013). Chitin, as a crystalline polysaccharide with high molecular weight, is the second most abundant organic compound, after cellulose on earth. It is considered as a natural fiber that is found in shells of marine animals, such as shrimps and lobsters, insect shells and in the wall of several fungi and yeasts (Rinaudo 2006; Kumari and Rath 2014). In its structure, chitin is often linked to the other major constituents of the carapace, forming covalent bonds with $30-40 \%$ proteins and 
a complex matrix containing $30-50 \%$ calcium and phosphate carbonate and $20-30 \%$ of chitin.

Chitosan (CS) is a cationic semi-crystalline polysaccharide having a linear chain of 2-amino-2-deoxy-D-glucopyranose and 2-acetamido-2-deoxy-D-glucopyranose repeating units linked by $\beta(1 \rightarrow 4)$ which can be obtained by deacetylation of chitin. Degree of deacetylation (DA) greater than $50 \%$ generally confirms the obtaining of CS (Younes et al. 2014). Chitosan has three reactive functional groups, amine, primary and secondary hydroxyls that offer potential for covalent and ionic modifications allowing the improvement of its mechanical and biological properties. In addition, CS is a biodegradable, nonallergenic, biocompatible, antibacterial, renewable, nontoxic product and largely used in biomedical and industrial fields as well as in industrial wastewater treatment (Kumar 2000). In the last years, several new forms of chitosan intended for wastewater treatment are produced in the form of films (Rizzi et al. 2018; Frantz et al. 2017), microcapsules (Tong 2017), composites (Xie et al. 2013), nanoparticles (Sivakami et al. 2013) and nanofibers (Nthunya et al. 2017) to improve its potential applications. Chitosan films could be obtained by various methods (Uragami et al. 2002) such as: (1) direct perversion of the chitosan solvent, (2) addition of bifunctional reactants to the chitosan and (3) air-drying of chitosan solutions. The use of chitosan films for polluted effluents by dyes appears to be economically more attractive than activated carbon (Sadeghi-Kiakhani et al. 2013).

Eriochrome black T (EBT) is an azoanionic dye with confirmed toxic and carcinogenic properties. It is widely used in textile dyeing industry (De Luna et al. 2013). Several studies have investigated the removal of EBT from aqueous solutions by various solid matrixes such as bioadsorbents and nanoparticles (Moeinpour et al. 2014).

Due to its chemical stability, its high reactivity and its affinity for the majority of anionic and cationic dyes, chitosan has been the subject of several studies for the elimination of dyes in aqueous solutions (Jiang et al. 2014; Kashif et al. 2016). This paper aims to (1) extract chitin from local source: shrimp shell, and to produce CS by two deacetylation methods depending on the used temperature, (2) to assess the composition and physicochemical properties of the produced CS through adapted measures such as conductometry and $\mathrm{pH}$ metric titration, viscosimetry, Fourier transform infrared spectroscopy (FTIR), X-ray diffraction (DRX) and differential scanning calorimetry (DSC), (3) to design CS film and assess its potential in removing EBT dye from aqueous solutions under various experimental conditions in batch mode (contact time, initial concentration, $\mathrm{pH}$ and temperature) and finally (4) to explore the main involved mechanisms in this adsorption process.

\section{Materials and methods}

\section{Used biomass origin and preparation}

The used shrimp shellfish for the extraction of chitosan was collected from Mers El Kebir port on the Mediterranean Sea, Oran Province (Northwest Algeria). The samples were carefully cleaned with distillated water and then dried at $80^{\circ} \mathrm{C}$ for 2 days. Finally, this dried biomass was ground into small pieces.

\section{Extraction of chitosan}

The extraction of CS from the collected shrimp shellfish was carried out according to Brine's methodology (Brine 1984). This protocol consists of the following tasks: (1) deproteinization where proteins related to chitin were removed through 2-day continuous stirring of $76.45 \mathrm{~g}$ of shrimp shellfish in $760 \mathrm{~mL}$ of $0.1 \mathrm{~N} \mathrm{NaOH}$ solution. Then, this solution was decanted at room temperature and filtered through filter paper. The obtained filtrate was afterward washed with distilled water until neutral $\mathrm{pH}$ and (2) demineralization that consists in removing the mineral matter bound to chitin. This step was performed through 8-day continuous stirring to rinse the obtained filtrate in $200 \mathrm{~mL}$ of $3-5 \% \mathrm{HCl}$ solution, followed by decantation, filtration and rinsing with distilled water. The obtained product after these two tasks is named chitin; (3) deacetylation: the obtained chitin (task 2 ) is chemically deacetylated in order to remove some or all of its acetyl groups. This chemical deacetylation is carried out by hydrolysis of chitin in a strongly alkaline medium with $50 \% \mathrm{NaOH}$ under agitation for $4 \mathrm{~h}$ at a controlled temperature. In our case, two temperatures were used: $40{ }^{\circ} \mathrm{C}$ to prepare the first type of chitosan (CS-I) and $90{ }^{\circ} \mathrm{C}$ to get the chitosan second type (CS-II) which is lighter pink than CS-I. The alkaline solution was filtered, and the filtrate was washed with distilled water at $50{ }^{\circ} \mathrm{C}$ with stirring time for $5 \mathrm{~h}$ until reaching a neutral medium. The resulting powders correspond to CS-I and CS-II (Fig. 1).

\section{Preparation of chitosan-based film}

The obtained CS-II was transformed in a chitosan film in order to be used as an adsorbent for the removal of EBT. This transformation was carried out through the following steps: (1) the stirring for $3 \mathrm{~h}$ at room temperature of $1 \mathrm{~g}$ of CS-II in $100 \mathrm{~mL}$ of $0.17 \mathrm{M}$ acetic acid, (2) the casting of the above CS solution in Petri dishes, (3) the immersion of the obtained CS film in $0.1 \mathrm{M} \mathrm{NaOH}$ for $1 \mathrm{~h}$ and finally (4) its washing with distilled water until attaining a neutral $\mathrm{pH}$. 


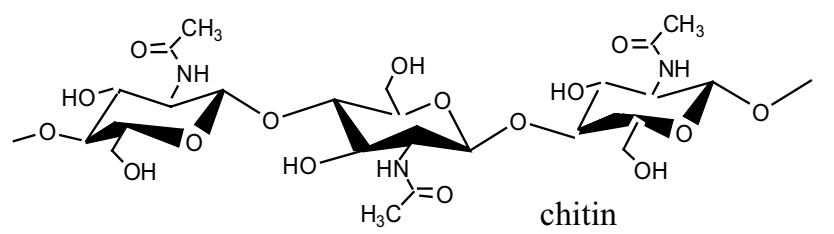

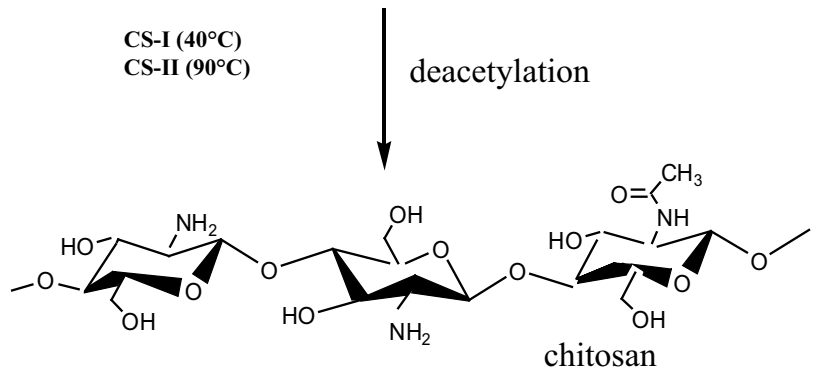

Fig. 1 Deacetylation mechanism

\section{Characterization of the produced chitosans}

The two produced chitosans were characterized through the following various methods.

\section{Determination of deacetylation degree by conductometric and $\mathrm{pH}$ metric measurement}

The conductometric measurement consists in dissolving $150 \mathrm{mg}$ of the studied chitosan (CS-I or CS-II) in $0.1 \mathrm{M} \mathrm{HCl}$ solution and then the titration of this solution with $0.1 \mathrm{~N}$ $\mathrm{NaOH}$ solution. The measure of the conductivity progress versus the added $\mathrm{NaOH}$ volume permits the determination of the equivalent volumes. DA is then calculated by the following equation (Yun Yang and Montgomery 1999):

$\mathrm{DA}=\frac{M_{1}\left(V_{2}-V_{1}\right) N}{m+M_{2}\left(V_{2}-V_{1}\right) N} 100 \%$

$N$ : $(\mathrm{NaOH})(\mathrm{mole} / \mathrm{L}), V_{2}$ and $V_{1}$ : equivalent volumes of $\mathrm{NaOH}$ used in titration, $m$ : weight of CS $(\mathrm{g}), M_{1}=203 \mathrm{~g} /$ mol: molecular weight of acetylated monomer, $M_{2}=42 \mathrm{~g} /$ mol: difference between molecular weight of acetylated monomer and molecular weight of deacetylated monomer.

In $\mathrm{pH}$ metric measurement, the DA was determined as follows (Tolaimate et al. 2000): $135 \mathrm{mg}$ of CS-I or CS-II was dissolved in $0.1 \mathrm{~N} \mathrm{HCl}$ solution and then titrated with $0.05 \mathrm{~N} \mathrm{NaOH}$ solution. A curve with two inflection points is generally obtained and allows the determination of the DA\% of the chitosan using Eq. (1).

\section{Determination of the chitosans' molecular weight}

The molecular weights of the produced chitosans (CS-I and CS-II) were determined by using Mark Houwink's equation (Kasaai 2007):
$[\eta]=K M^{a}$

where $(\eta)$ is the intrinsic viscosity that was determined by using a capillary viscometer (type KPG Cannon-Fenske), $M$ is the average molecular weight of polymer, $K$ and $a$ are constants that depend on the used polymer-solvent system. They were fixed to 0.72 and $4.74 .10^{-5} \mathrm{dL} / \mathrm{g}$, respectively.

\section{Fourier transform infrared spectroscopy (FTIR)}

Infrared spectra of CS were obtained over frequency range of 400-4000 $\mathrm{cm}^{-1}$ using a FTIR Spectra (Bruker alpha-P) equipped with an ATR diamond (without solvent, without $\mathrm{KBr}$ ). The CS-I or CS-II powder was simply placed into the sample cup and analyzed without any prior preparation.

\section{X-ray diffraction (XRD)}

Wide-angle X-ray diffraction analyses were performed in order to determine the crystallinity of the extracted CS using a diffractometer XRD (Bruker model D8 ADVANCE). Data were collected at a scan rate of $1 \%$ min with scan angle from $2^{\circ}$ to $40^{\circ}$.

\section{Differential scanning calorimetry (DSC)}

Thermal analysis was carried out by a differential scanning calorimeter (Netzsch DSC-214 polyma) where $10 \mathrm{mg}$ of the sample was put in the crucible with a heating time and rate of $45 \mathrm{~min}$ and $10{ }^{\circ} \mathrm{C} / \mathrm{min}$, respectively.

\section{Point of zero charge}

The $\mathrm{pH}$ at point of zero charge $\left(\mathrm{pH}_{\mathrm{PZC}}\right)$ is an important parameter in order to get a better understanding of the surface adsorption mechanism. To determine $\mathrm{pH}_{\mathrm{PZC}}, 1 \mathrm{~cm}^{2}$ of the used chitosan film was shaken for $24 \mathrm{~h}$ in $20 \mathrm{~mL}$ of $0.01 \mathrm{M} \mathrm{NaCl}$ solutions for initial various $\mathrm{pHs}$ varying from 3 to 12 . These solutions' $\mathrm{pH}$ values were adjusted by using $0.1 \mathrm{M} \mathrm{HCl} / \mathrm{NaOH}$ solutions. The $\mathrm{pH}_{\mathrm{PZC}}$ is defined as the point at which the curve initial $\mathrm{pH}$ versus final $\mathrm{pH}$ crosses the line initial $\mathrm{pH}=$ final $\mathrm{pH}$ (Nordine et al. 2016).

\section{Preparation and analysis of Eriochrome black T}

Eriochrome black T $\left(\mathrm{C}_{20} \mathrm{H}_{12} \mathrm{~N}_{3} \mathrm{O}_{7} \mathrm{SNa}, \mathrm{MW}=461,381 \mathrm{~g} / \mathrm{mol}\right)$, supplied by MERCK Scientific, North America (Fig. 2), was used during the adsorption batch tests. An EBT stock solution with a concentration of $1 \mathrm{~g} / \mathrm{L}$ was prepared with distilled water and used throughout this study for the preparation of different solutions. 
<smiles>O=[N+]([O-])c1ccc2c(/N=N\c3ccc4ccccc4c3O)c(O)cc(S(=O)(=O)O)c2c1</smiles>

Fig. 2 Structure of Eriochrome black T (EBT)

The dye concentrations were determined by measuring the absorbance at the characteristic wavelength $(540 \mathrm{~nm})$ using a double-beam UV/Vis spectrophotometer (Shimadzu 2401).

\section{Adsorption experiments}

\section{Kinetic study}

EBT adsorption experiments were performed by batch technique at $20 \pm 2{ }^{\circ} \mathrm{C}$ by immersing $1 \mathrm{~cm}^{2}$ of the CS-II film into $120 \mathrm{~mL}$ capped flasks containing EBT at a concentration of $100 \mathrm{mg} / \mathrm{L}$ at a constant agitation speed of $500 \mathrm{rpm}$ and $\mathrm{pH}$ of 6.10. EBT adsorption kinetic was followed at contact times of $2,5,10,15,20,30,40,60,80,110,140,170,240 \mathrm{~min}$. The dye adsorbed amount $\left(q_{t}(\mathrm{mg} / \mathrm{g})\right)$ and efficiency $(\mathrm{AE}(\%))$ at a given time, $\mathrm{t}$, were calculated by using the following equations:

$q_{t}=\frac{C_{i}-C_{t}}{m} V$

$\mathrm{AE}(\%)=\frac{C_{i}-C_{t}}{C_{i}} \times 100$

where $C_{i}$ and $C_{t}(\mathrm{mg} / \mathrm{L})$ are the measured initial and at time ' $t$ ' of EBT concentration; $V$ is the synthetic effluent volume and $m(g)$ is the adsorbent mass.

The kinetic modeling of EBT adsorption was fitted with the well-known models (Zubair et al. 2017), namely pseudofirst order and pseudo-second order (Table 1).

\section{Effect of initial dye concentration}

The effect of the initial EBT concentration on its removal by CS-II film was assessed for concentrations of 50, 100, 150 and $200 \mathrm{mg} / \mathrm{L}$. These experiments were performed for fixed adsorbent surface, aqueous $\mathrm{pH}$ and temperature of $1 \mathrm{~cm}^{2}$, 6.10 , and $20 \pm 2{ }^{\circ} \mathrm{C}$, respectively.

\section{Effect of $\mathrm{pH}$}

The effect of $\mathrm{pH}$ on the EBT efficiency was analyzed at various $\mathrm{pH}$ values ranging from 3 to 9 at a temperature of $20 \pm 2{ }^{\circ} \mathrm{C}, 200 \mathrm{mg} / \mathrm{L}$ of EBT dye and for contact time of $50 \mathrm{~min}$.

\section{Effect of temperature}

The effect of the solution temperature on EBT dye adsorption was investigated at different temperatures of 20, 30, 40 and $50{ }^{\circ} \mathrm{C}$ for an initial dye concentration of $200 \mathrm{mg} / \mathrm{L}$ and a contact time of $50 \mathrm{~min}$.

\section{Adsorption isotherms}

The adsorption isotherm describes the relationship between the amount of EBT dye adsorbed by the adsorbent (CS-II film) and the concentration of remaining dye in the solution at constant temperature. The adsorption mechanism was studied using the most common isotherms models: Langmuir and Freundlich model. The empirical Freundlich isotherm model describes the adsorption on heterogeneous surfaces, while the Langmuir isotherm refers to homogeneous adsorption where all sites possess equal affinity for the adsorbate (Foo and Hameed 2010). The original and linear forms of these two models are given in Table 1 in which $q_{e}$ and $q_{t}(\mathrm{mg} / \mathrm{g})$ are sorption capacities at equilibrium and at time $t$, respectively, $k_{1}$ and $k_{2}$ are rates constants of the firstorder and second-order models, respectively, $C_{e}(\mathrm{mg} / \mathrm{L})$ is the EBT concentration at equilibrium, $q_{m}(\mathrm{mg} / \mathrm{g})$ is the theoretical maximum adsorbed amount, $K_{\mathrm{L}}(\mathrm{L} / \mathrm{mg})$ is Langmuir constant and $K_{\mathrm{F}}$ is Freundlich empirical constant.
Table 1 Used models for the kinetic and isotherm studies

\begin{tabular}{|c|c|c|c|c|}
\hline Model & Equation & Linear forms & & References \\
\hline \multicolumn{5}{|l|}{ Kinetic models } \\
\hline Pseudo-first order & $\frac{\mathrm{d} q_{e}}{\mathrm{~d} t}=k_{2}\left(q_{e}-q_{t}\right)^{2}$ & $\ln \left(q_{e}-q_{t}\right)=\ln q_{e}-k_{1} t$ & (5) & \\
\hline Pseudo-second order & $\frac{\mathrm{d} q_{e}}{\mathrm{~d} t}=k_{1}\left(q_{e}-q_{t}\right)$ & $\frac{t}{q_{t}}=\frac{1}{k_{2} q_{e}^{2}}+\frac{t}{q_{e}}$ & (6) & Lagergren (1898) \\
\hline \multicolumn{5}{|l|}{ Isotherm models } \\
\hline Langmuir & $q_{e}=\frac{q_{m} K_{\mathrm{L}} C_{e}}{1+K_{\mathrm{L}} C_{e}}$ & $\frac{C_{e}}{q_{e}}=\frac{1}{k_{1} q_{m}}+\frac{C_{e}}{q_{m}}$ & (7) & Langmuir (1918) \\
\hline Freundlich & $q_{e}=K_{\mathrm{F}} C_{e}^{1 / n}$ & $\ln q_{e}=\ln K_{\mathrm{F}}+\frac{1}{n} \ln C_{e}$ & (8) & Freundlich (1907) \\
\hline
\end{tabular}


The equilibrium adsorption experiments were performed by immersing $1 \mathrm{~cm}^{2}$ of CS film in $100 \mathrm{~mL}$ of EBT solution at initial concentrations of 50,100, 150, 200 and $300 \mathrm{mg} / \mathrm{L}$ at a temperature of $20 \pm 2{ }^{\circ} \mathrm{C}$, pH of 4.66 and for a contact time of $50 \mathrm{~min}$. This time was determined on the basis of preliminary experiments to be sufficient to attain an equilibrium state characterized by quasi-constant residual EBT concentrations in the aqueous phase.

\section{Results and discussion}

\section{Adsorbent characterization}

Extracted chitosan was characterized through the assessment of its degree of deacetylation, its molecular weight, its $\mathrm{pKa}$ and solubility (Table 2 and Fig. 3) as well as specific analyses such as FTIR, DSC and XRD analysis (Fig. 4).

Table 2 indicates that the degree of deacetylation of the extracted chitosan at $90{ }^{\circ} \mathrm{C}$ is higher than the one corresponding to the chitosan produced at $40{ }^{\circ} \mathrm{C}$ due to the presence of more amine groups generated during deacetylation processes. Similar results were reported by Tsaih and Chen (2003) who confirmed that an increase in temperature can enhance the removal of acetylamide $\left(-\mathrm{NHCOCH}_{3}\right)$ groups from chitin resulting in an increase in amino groups $\left(-\mathrm{NH}_{2}\right)$ in chitosan.

The presence of primary amine functions in the structure of CS translated basic character with $\mathrm{pKa}=6.02$ for CS-I and 6.49 for CS-II in agreement with the pKa of 6.17 found by Wang et al. (2006) for a degree of deacetylation of $93 \%$. Furthermore, with the higher deacetylation temperature, the molecular weight of chitosan was lower (Table 2); this behavior could be explained as earlier: the number of acetylamide $\left(-\mathrm{NHCOCH}_{3}\right)$ group decreased when increasing deacetylation temperature, and as a result a decrease in molecular weight was observed (Fig. 3).

The CS solubility tests confirmed that both CS-I and CS-II were insoluble in water. Furthermore, CS-II was more soluble in acidic media $\left(\mathrm{HCl}\right.$ and $\left.\mathrm{CH}_{3} \mathrm{COOH}\right)$ than CS-I. This phenomenon can be explained by the fact that chitosan with higher DA (CS-II) possesses more amino groups; at low $\mathrm{pH}$, the free amino groups are protonated causing electrostatic repulsion between the polymer's chains which is more pronounced in the case of CS-II, thus promoting its solubility (Pavinatto et al. 2012). On the other hand, the presence of $\mathrm{N}$-acetyl group in the chain (at low DA) increases its hydrophobic character and modified its solubility in the solution because of the formation of hydrogen bonds (Philippova et al. 2010).

FTIR investigations (Fig. 4a) showed a stretching vibration band in CS-II larger than CS-I in the range of $3450-3200 \mathrm{~cm}^{-1}$ corresponding to $\mathrm{NH}$ (primary and secondary) and $\mathrm{OH}$. The $\mathrm{NHCOCH}_{3}$ and $\mathrm{CH}_{2} \mathrm{OH}$ groups in pyranose ring were observed in the range of 2880-2960 $\mathrm{cm}^{-1}$. Major absorption bands were observed between 1200 and $1000 \mathrm{~cm}^{-1}$ and were attributed to free amine $\left(-\mathrm{NH}_{2}\right)$ in position $\mathrm{C}_{2}$ of glucosamine present in $\mathrm{CS}$. The peak at $1624 \mathrm{~cm}^{-1}$ could be based on to the stretching of C-N vibration, linked to $\mathrm{OH}$ group by bonding (Rinaudo 2006), and the adsorption band at $1377 \mathrm{~cm}^{-1} \mathrm{~g}$ represents the $\mathrm{C}-\mathrm{O}$ stretching of primary alcohol group. The bands at 1100 , 1060 and $1024 \mathrm{~cm}^{-1}$ showed $\mathrm{C}-\mathrm{O}$ stretching of polysaccharide bond. During the deacetylation reaction of chitin at $40{ }^{\circ} \mathrm{C}$ and $90{ }^{\circ} \mathrm{C}$ carried out under the same alkaline conditions, intensification of all the bands with an overlap of the peaks between (1600-1660) $\mathrm{cm}^{-1}$ (amide I) was observed to give a single larger peak indicating a decrease in acetyl groups and hydrogen bonds. According to Kumari and Rath (2014), the band at $1597 \mathrm{~cm}^{-1}$ has a larger intensity than at $1655 \mathrm{~cm}^{-1}$ which suggested that the deacetylation process was effective. The intensity in the $(3000-3400) \mathrm{cm}^{-1}$ region attributed to inter- and intramolecular $\mathrm{H}$ bonds suggests a decrease in these regions in agreement with the intensity observed in the region (1660-1600) $\mathrm{cm}^{-1}$. This result has been confirmed in previous works (Rinaudo 2006).

The diffractogram of CS-I (Fig. 4b) showed three major peaks at $2 \theta$ around $30^{\circ}$ and $40^{\circ}$ and two minor peaks around $9^{\circ}-10^{\circ}$ and $20^{\circ}-21^{\circ}$ which reflects the presence of different chitin structures in CS-I, while the diffractogram of CS-II showed two crystalline major peaks of strong reflections at $10^{\circ}$ and $20^{\circ}$ and confirms that the crystallinity of CS-II increases with increasing DA. This result is in agreement with the literature (Yen et al. 2009; Muzzarelli et al. 2007).

The thermal analysis of CS-I and CS-II showed a wide endothermic peak at $100{ }^{\circ} \mathrm{C}$ and $120{ }^{\circ} \mathrm{C}$ for CS-I and CS-II, respectively (Fig. 4c). Similar observations have been made by Yuan et al. (2011). The difference in endothermic peaks could be explained by change in mechanism of water retention. Two peaks were observed at $300{ }^{\circ} \mathrm{C}$ and $290{ }^{\circ} \mathrm{C}$ for CS-II and CS-I indicating exothermic peaks that may be
Table 2 Characteristics of the extracted CS from shrimp shell

\begin{tabular}{|c|c|c|c|c|c|c|c|}
\hline & $\begin{array}{l}\text { Tempera- } \\
\text { ture }\left({ }^{\circ} \mathrm{C}\right)\end{array}$ & $\begin{array}{l}\text { DA (conducto- } \\
\text { metric titration) }\end{array}$ & $\begin{array}{l}\text { DA ( } \mathrm{pH} \text { met- } \\
\text { ric titration) }\end{array}$ & Mean of DA & $\mathrm{pKa}$ & $\left(\eta_{\mathrm{red}}\right)(\mathrm{dL} / \mathrm{g})$ & $M(\mathrm{kDa})$ \\
\hline CS-I & 40 & $63 \%$ & $69 \%$ & $66 \%$ & 6.02 & 0.523 & 412 \\
\hline CS-II & 90 & $88.90 \%$ & $85.16 \%$ & $87 \%$ & 6.49 & 0.469 & 354 \\
\hline
\end{tabular}




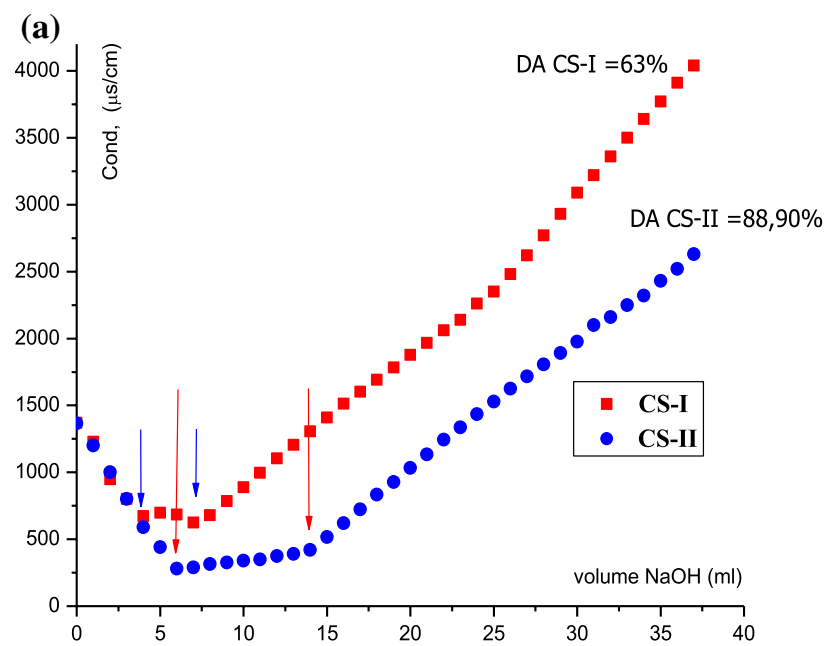

(b)

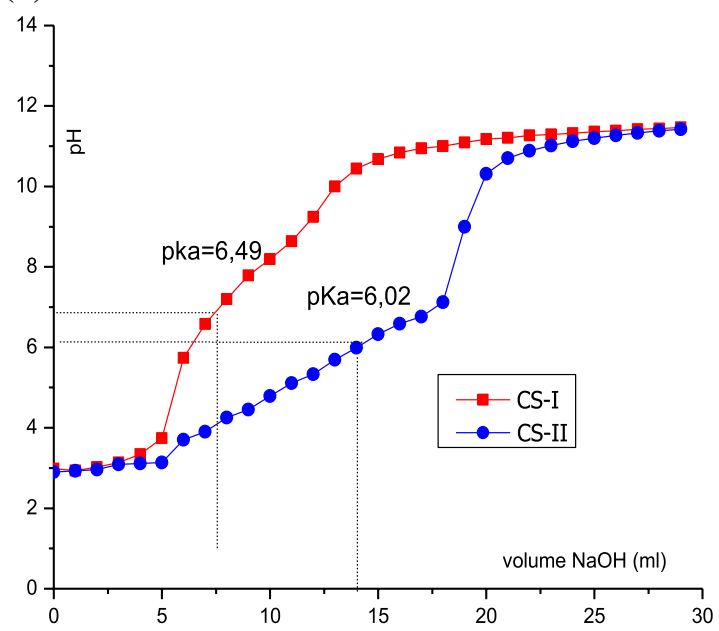

(c)

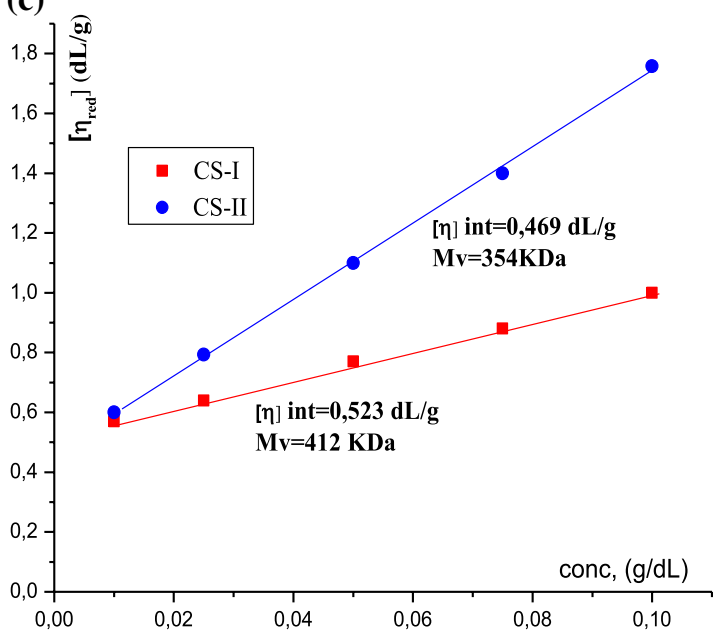

Fig. 3 Determination of DA of CS-I and CS-II by a conductometric measurements, $\mathbf{b} \mathrm{pH}$ metric measurements, $\mathbf{c}$ determination of Molecular weight by viscosimetry measurements $\left(T=30^{\circ} \mathrm{C}\right)$ related to the decomposition of amine units (Guinesi and Cavalheiro 2006).

Given these findings, CS-II was effectively extracted from shrimp shell waste and exhibited interesting characteristics in term of stability, molecular weight and degree of deacetylation.

\section{Kinetic and thermodynamic studies of EBT removal}

The effect of contact time on EBT adsorption onto CS-II film was investigated first. The adsorbed amount of dye on the CS-II film increased pronouncedly during the first 5-20 min of contact time and reached a maximum of $413 \mathrm{mg}$ of EBT per g of CS-II film about $50 \mathrm{~min}$ (Fig. 5a). After $50 \mathrm{~min}$, the amount of dye adsorbed was almost constant, indicating that equilibrium conditions have been attained. The rapid EBT dye adsorption in the first 5-20 min can be attributed to the availability of the active sites on the adsorbent surface. Therefore, $50 \mathrm{~min}$ is fixed as the optimum contact time.

Figure 5a also shows that the amount of EBT dye adsorbed at equilibrium increases with an increase in dye concentration. This may be due to the increase in the number of EBT molecules which results in more contacts between dye and adsorbent. Consequently, a higher initial EBT dye concentration enhances the sorption process leading to a higher adsorption capacity (Yagub et al. 2014).

To evaluate the performance of CS-II film for EBT removal from aqueous solutions and predict the mechanism of the sorption process, pseudo-first-order and pseudo-second-order kinetic models were applied on the experimental data. The linear forms of these two models are expressed by Eqs. (5) and (6), respectively (Table 1), where $k_{1}$ and $k_{2}$ are the pseudo-first-order and pseudo-second-order rate constant and $q_{e}$ and $q t$ are the adsorption capacities at equilibrium and at time $\mathrm{t}$, respectively. The values of $k_{1}, k_{2}$ and $q_{e}$ were calculated from the slope and intercept of the linear plots of Eqs. (5) and (6). The correlation coefficient was frequently used to decide whether the model represents correctly the experimental data. From Table 3 data and Fig. 6, it becomes clear that the pseudo-second-order model gave a better correlation $\left(R^{2}=0.9999\right)$ for the adsorption of EBT dye in comparison to the pseudo-first-order model and the theoretical qe value was closely similar to the experimental value. This is an indication that the rate-limiting step in the adsorption of EBT dye onto chitosan-based film involves chemisorption with the establishment of strong electronic bonding between dye molecules and the surface functional sites. Similar behavior has been observed by Zubair et al. 2017.

Figure $5 \mathrm{~b}$ displays the influence of the initial $\mathrm{pH}$ on the EBT adsorption capacity onto CS-II film. It could be clearly seen that the adsorption process is favorable in acidic medium. The increase in the adsorption capacity at lower 


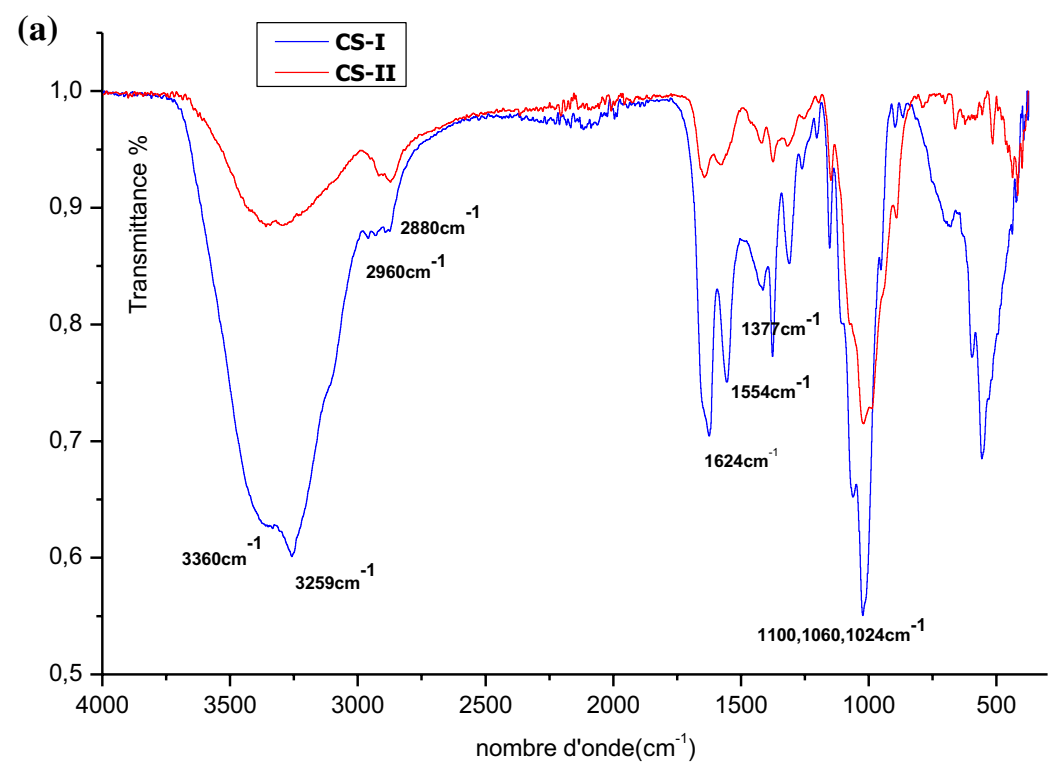

(b)
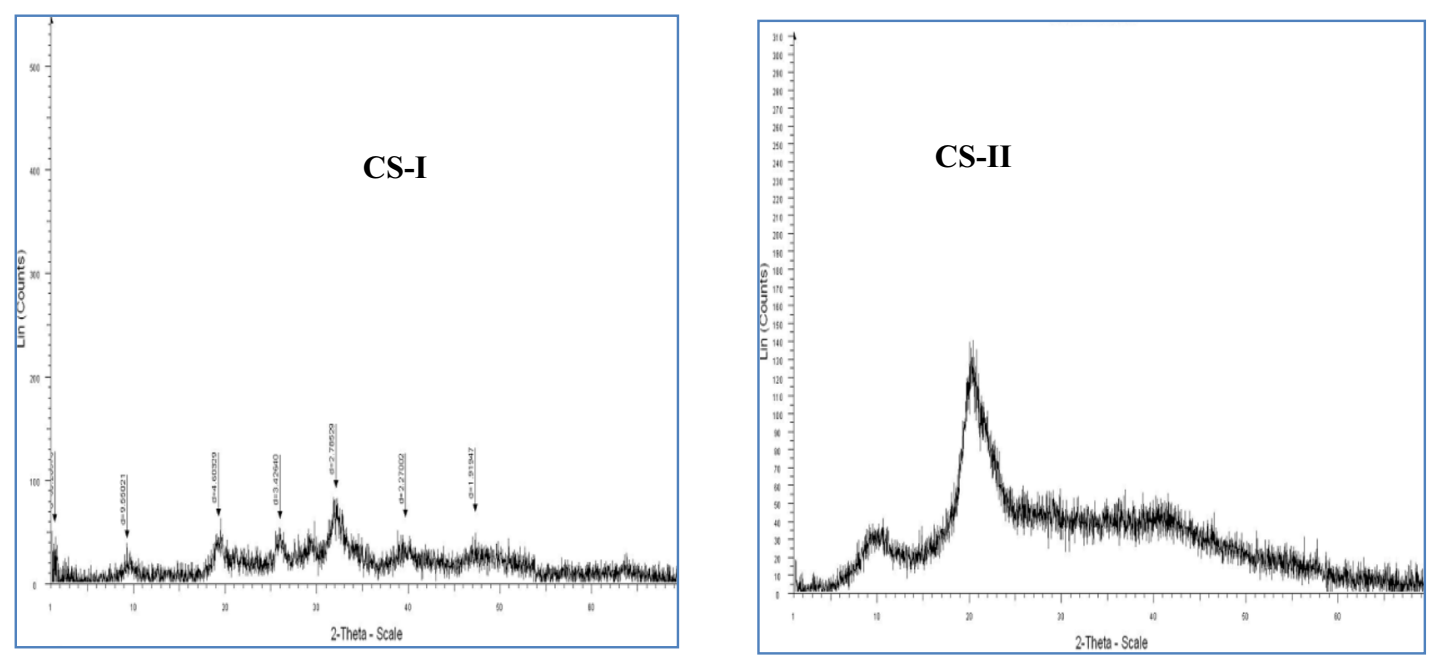

(c)
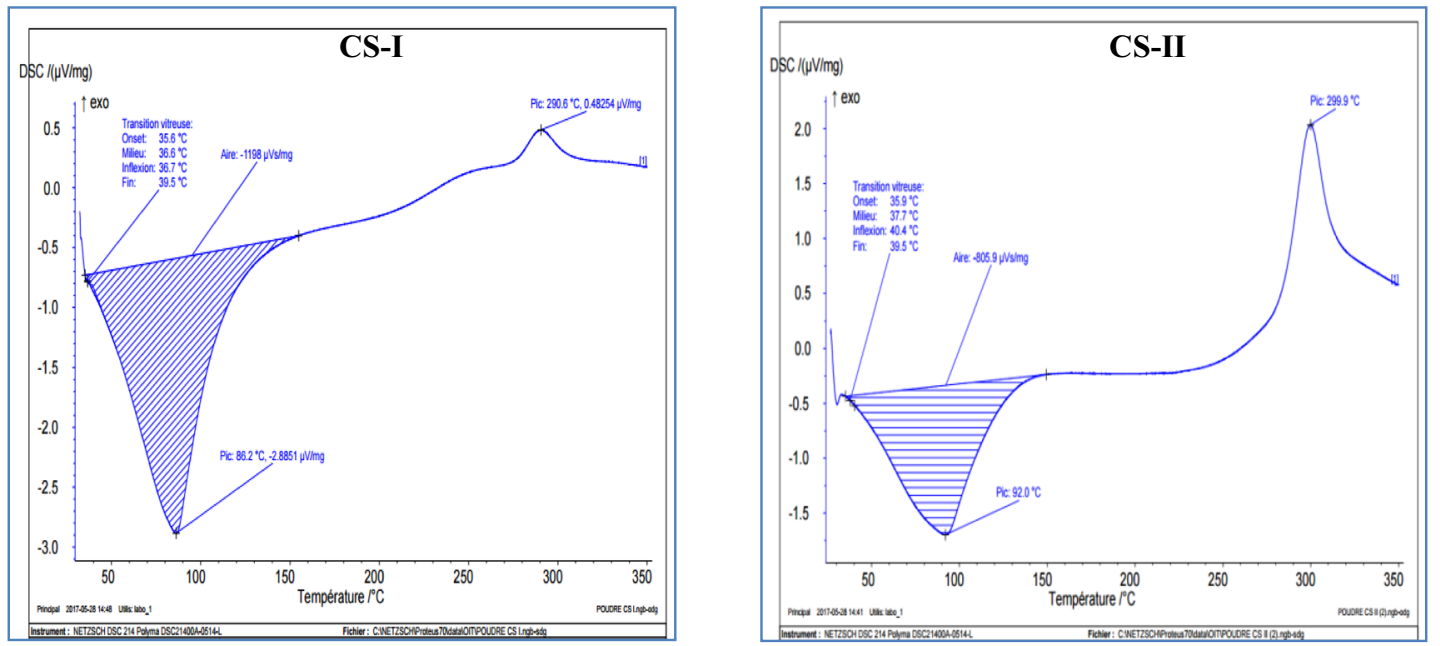

Fig. 4 Characterization of CS-I and CS-II a FTIR Spectra, b X-ray diffractogram, c DSC thermogram 

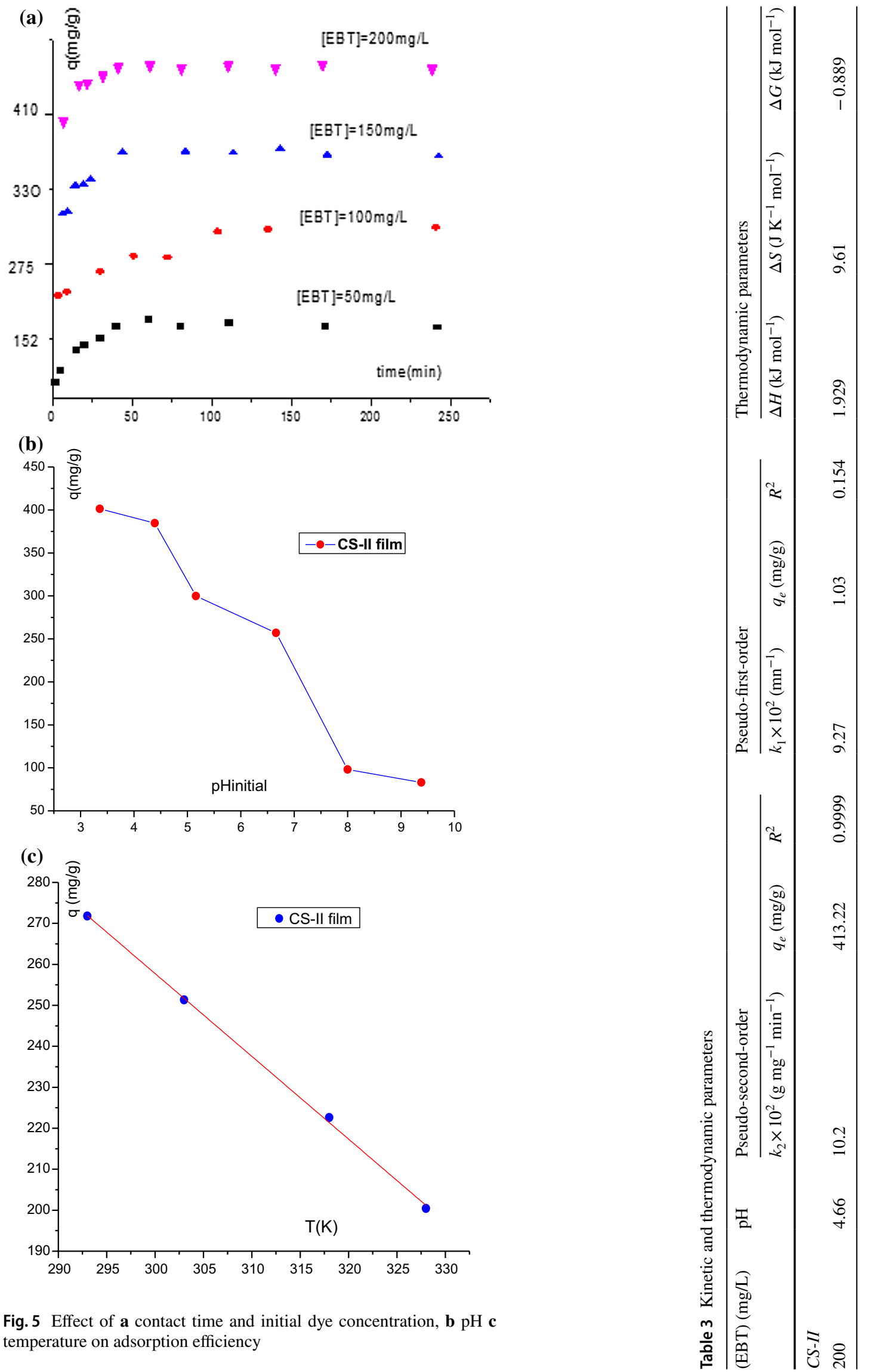

Fig. 5 Effect of a contact time and initial dye concentration, $\mathbf{b} \mathrm{pH} \mathbf{c}$ temperature on adsorption efficiency 
$\mathrm{pH}$ could be explained by: (1) the protonation of free amine groups in the CS-II film increases the electrostatic attractions with the negatively charged EBT ions (Kumar 2000), (2) in the surface charge of the adsorbent, the pHzpc of CS-II film was about 8.1(Fig. 7), and below this value, the CS-II film surface was positively charged and anionic EBT dye adsorption occurs easily. At pH higher than pHzpc, the CS-II film surface has a negative charge leading to electrostatic repulsions between negatively EBT species and negatively charged film and this result in a decrease of the anionic dye uptake (Attallah et al. 2016).

Testing under $20^{\circ} \mathrm{C}, 30^{\circ} \mathrm{C}, 40^{\circ} \mathrm{C}$ and $50{ }^{\circ} \mathrm{C}$ (Fig. 5c), the adsorption capacity of chitosan film decreases with the increase in temperature. It is well known that temperature
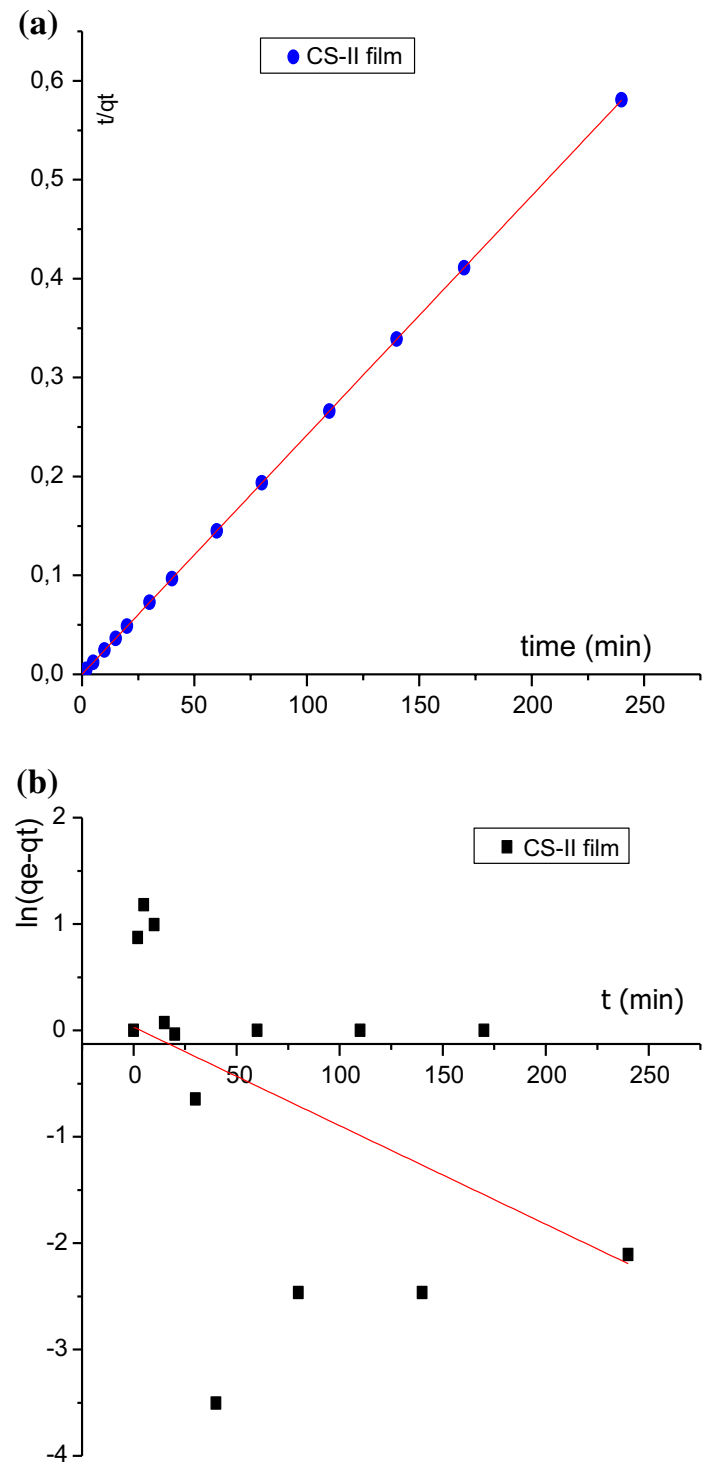

Fig. 6 Kinetic study of EBT adsorption on CS-II film a pseudo-second order, $\mathbf{b}$ pseudo-first order

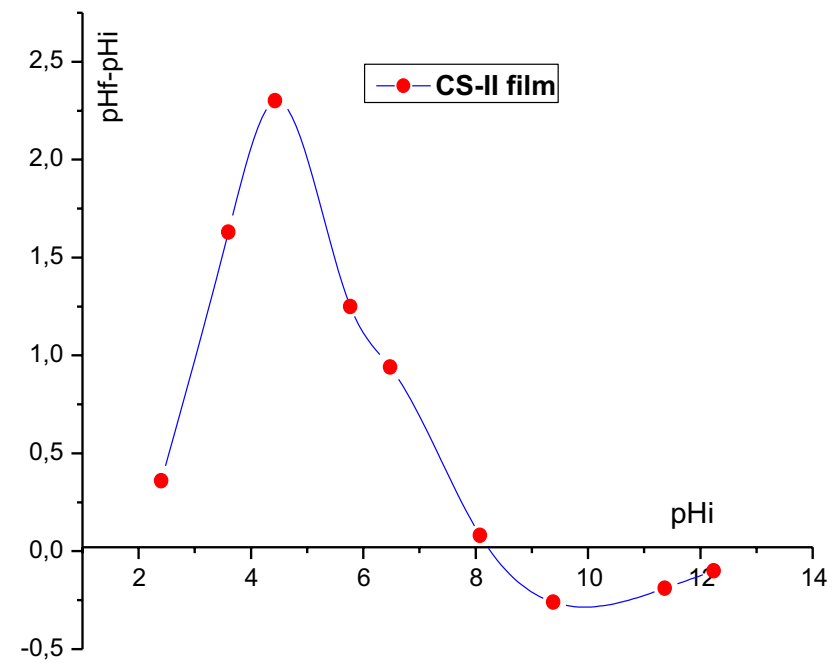

Fig. 7 Determination of pHpzc of CS-II film

has a positive effect on several dye adsorption properties such as the mobility of dye molecules, the number of active sites and the interactions between the adsorbate and adsorbent (Saber-Samandari et al. 2014). In our case, at higher temperatures, adsorbent-adsorbate interactions are overcome by EBT kinetic energy and as a consequence the adsorption process is not efficient, and similar observations have been reported by Wang et al. (2013) and Vaz et al. (2017) when investigating methylene blue removal by alginate and chitosan-based composites.

Thermodynamic parameters, changes in the Gibbs free energy $(\Delta G)$, enthalpy $(\Delta H)$ and entropy $(\Delta S)$ were calculated by using the following equations:

$\ln \left(\frac{q_{e}}{C_{e}}\right)=\frac{\Delta S}{R}-\frac{\Delta H}{R T}$

$\Delta G=\Delta H-T \Delta S$

where $R$ is the universal gas constant $(8.314 \mathrm{~J} / \mathrm{mol} / \mathrm{K}), T$ is the adsorption temperature $(\mathrm{K}),\left(q_{e} / C_{e}\right)$ is the thermodynamic equilibrium constants according to Xin et al. (2011). The plot of $\ln \left(q_{e} / C_{e}\right)$ against $1 / T$ is presented in Fig. 8 (straight line with $R^{2}=0.997$ ) where the $\Delta H$ and $\Delta S$ can be calculated from the slope and intercept of the fit, respectively. The calculated thermodynamic data are summarized in Table 3. The negative value of $\Delta G$ suggests that the adsorption is a spontaneous process and confirms its feasibility. In addition, the calculated $\Delta G$ at given temperatures $20,30,40$ and $50{ }^{\circ} \mathrm{C}$ was $-0.885,-0.981,-1.126$ and $-1.222 \mathrm{~kJ} \mathrm{~mol}^{-1}$, respectively. This demonstrates that for EBT dye, the spontaneous nature of the adsorption is inversely proportional to temperature. The greater negative $\Delta G$ value indicates a more favorable adsorption which was confirmed by the highest adsorption capacity obtained at 


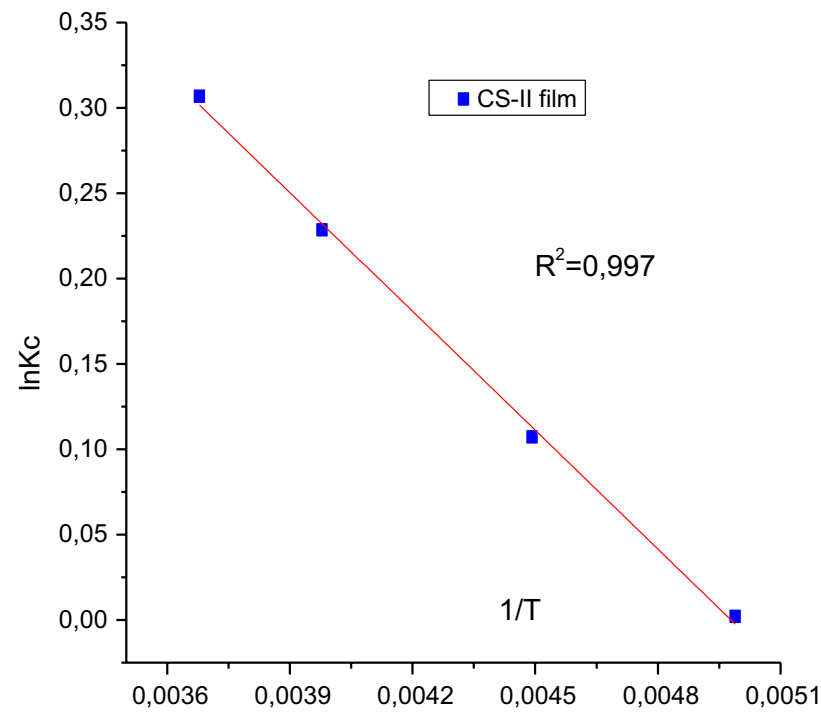

Fig. 8 Plot of $\ln K$ against $1 / T$

$20{ }^{\circ} \mathrm{C}$. The positive value of $\Delta H$ suggests that EBT adsorption onto chitosan film is endothermic in nature and the positive value of $\Delta S$ reveals the increased randomness at interface (solid/liquid) during adsorption.

\section{Adsorption isotherm}

The fitted equilibrium data with the Langmuir isotherm model are plotted in Fig. 9a by plotting $C_{e} / q_{e}$ against $C_{e}$, and the $Q_{\max }$ and $K_{\mathrm{L}}$ (Table 4) can be obtained from the intercepts and slopes. The $C_{e} / q_{e}$ against $C_{e}$ shows an approximate linear relation with low coefficient of determination $R^{2}$ of 0.504 . For the Freundlich model, the $K_{\mathrm{F}}$ and $1 / n$ (Table 4) are calculated from the plot of $\ln q_{e}$ against $\ln$ $C_{e}$ (Fig. 9b) which gives a good linear relation with the $R^{2}$ of 0.992; this suggests that Freundlich model was the most fitted to our experimental data, has good agreement with experimental qe $(413 \mathrm{mg} / \mathrm{g})$ and assumes heterogeneous multilayer adsorption.

The calculated value of Freundlich exponent " $n$ " was equal to 1.064 , in the range of $1-10$, which indicates a favorable adsorption of EBT onto chitosan-based film (Foo and Hameed 2010).

Table 4 Freundlich and Langmuir parameters for EBT adsorption isotherms

\begin{tabular}{lllllll}
\hline \multicolumn{2}{l}{ Freundlich isotherm model } & & \multicolumn{3}{l}{ Langmuir isotherm model } \\
${$\cline { 1 - 2 }$/ \mathrm{g})} \begin{array}{l}K_{\mathrm{F}}\left(\mathrm{mg}^{1-1 / n}\right. \\
\left.L^{1 / n} \mathrm{~g}^{-1}\right)\end{array} }$ & $R^{2}$ & & $\begin{array}{l}Q_{\max } \times 10^{-1} \\
(\mathrm{mg} / \mathrm{g})\end{array}$ & $K_{\mathrm{L}}(\mathrm{L} / \mathrm{mg})$ & $R^{2}$ \\
\hline 0.94 & 2.6566 & 0.992 & & 369.22 & 0.5932 & 0.504 \\
\hline
\end{tabular}
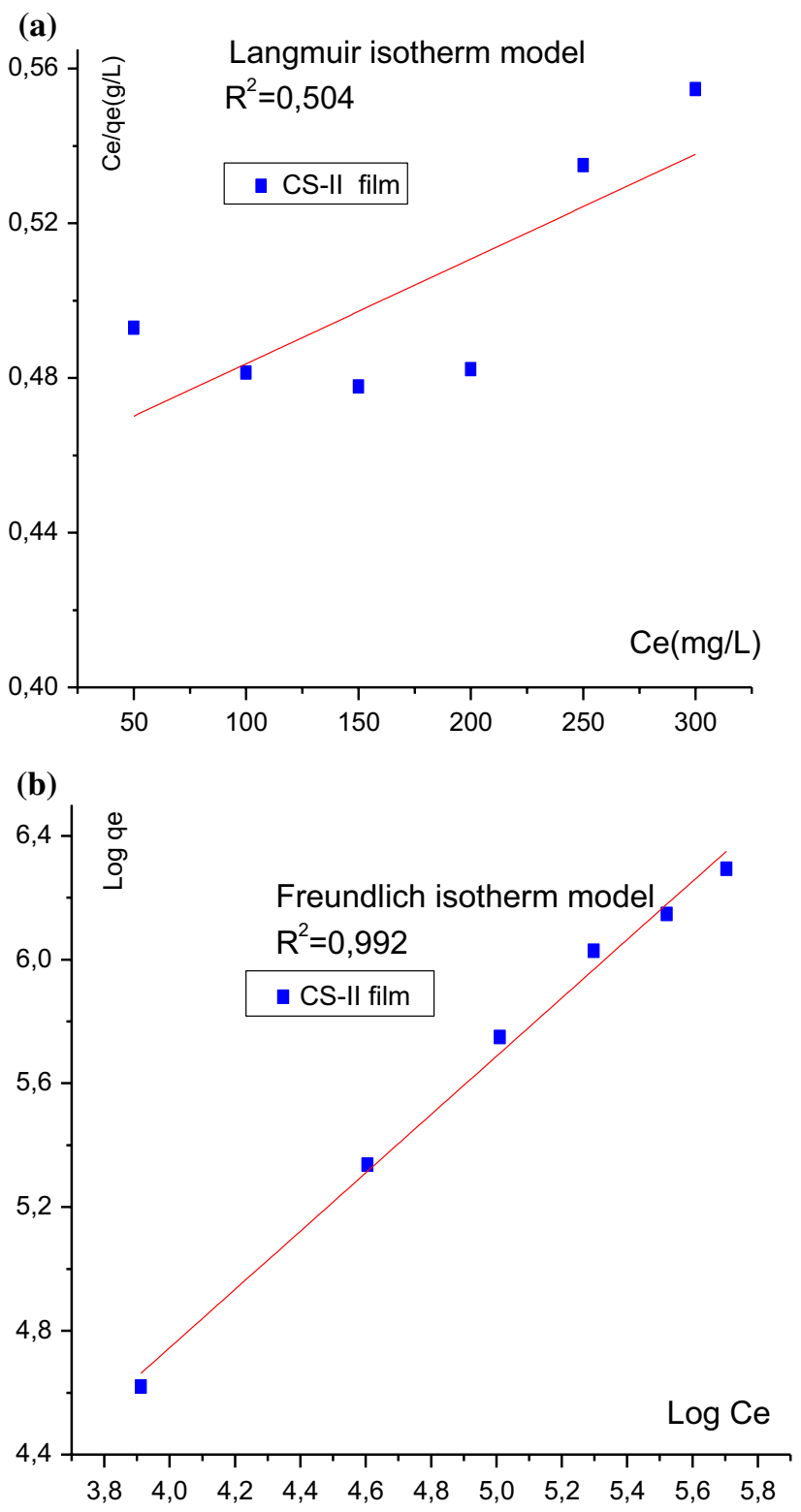

Fig. 9 Adsorption isotherm a Langmuir plot, b Freundlich plot

\section{Conclusion}

Chitosan has been successfully prepared from local shrimp shellfish with two deacetylation temperatures at $40{ }^{\circ} \mathrm{C}$ and $90^{\circ} \mathrm{C}$. Functional and physicochemical properties of CS produced have been evaluated by several methods such as conductometry, $\mathrm{pH}$ metry, viscosimetry, FTIR, XRD and DSC. The evolution of DA by increasing temperature affected molecular weight, viscosity, crystallinity and stability of CS. On the other hand, performance of CS film prepared for removal of Eriochrome black $\mathrm{T}$ has been tested, and the results revealed that chitosan-based film exhibited a high adsorption capacity of EBT dye at $\mathrm{pH}$ acid and ambient 
temperature. The kinetics of adsorption were found to be of pseudo-second order with a high correlation coefficient $\left(R^{2}=0.9999\right)$. The thermodynamic study showed that adsorption of Eriochrome black T dye on CS film was an endothermic and spontaneous process. Freundlich model fitted well to the experimental data, and the numerical value of $n=1.064$ indicates that adsorption of EBT onto CS film is favorable.

\section{Compliance with ethical standards}

Conflict of interest The authors declare that they have no conflict of interest.

Open Access This article is distributed under the terms of the Creative Commons Attribution 4.0 International License (http://creativeco mmons.org/licenses/by/4.0/), which permits unrestricted use, distribution, and reproduction in any medium, provided you give appropriate credit to the original author(s) and the source, provide a link to the Creative Commons license, and indicate if changes were made.

\section{References}

Akrout H, Jellali S, Bousselmi L (2015) Enhancement of methylene blue removal by anodic oxidation using BDD electrode combined with adsorption onto sawdust. C R Chim 18(1):110-120

Attallah OA, Al-Ghobashy MA, Nebsen M, Salem MY (2016) Removal of cationic and anionic dyes from aqueous solution with magnetite/pectin and magnetite/silica/pectin hybrid nanocomposites: kinetic, isotherm and mechanism analysis. RSC Adv 6:11461-11480

Azzaz AA, Jellali S, Souissi R, Ergaieg K, Bousselmi L (2017) Alkaline-treated sawdust as an effective material for cationic dye removal from textile effluents under dynamic conditions: breakthrough curve prediction and mechanism exploration. Environ Sci Pollut Res Int 24(22):18240-18256

Bharathi KS, Ramesh ST (2013) Removal of dyes using agricultural waste as low-cost adsorbents: a review. Appl Water Sci 3:773-790

Brine CJ (1984) Chapters in Chitin. In: Zikakis JP (ed) Chitosan and related enzymes. Academic Press Inc, Cambridge, pp 17-23

De Luna MDG, Flores ED, Genuino DAD, Futalan CM, Wan MW (2013) Adsorption of Eriochrome Black T (EBT) dye using activated carbon prepared from waste rice hulls-optimization, isotherm and kinetic studies. J Taiwan Inst Chem Eng 44(4):646-653

Foo KY, Hameed BH (2010) Insights into the modeling of adsorption isotherm systems. Chem Eng J 156:2-10

Fosso-Kankeu E, Webster A, Ntwampe IO, Waanders FB (2017) Coagulation/flocculation potential of polyaluminium chloride and bentonite clay tested in the removal of methyl red and crystal violet. Arab J Sci Eng 42(4):1389-1397

Frantz TS, Silveira N Jr, Quadro MS, Andreazza R, Barcelos AA, Cadaval TRS Jr, Pinto LAA (2017) Cu(II) adsorption from copper mine water by chitosan films and the matrix effects. Environ Sci Pollut Res Int 24(6):5908-5917

Freundlich H (1907) Ueber die adsorption loesungen zeitsh. Phys Chem 57:385-470
Guinesi LS, Cavalheiro ETG (2006) The use of DSC curves to determine the acetylation degree of chitin/chitosan samples. Thermochim Acta 444:128-133

Jiang X, Sun Y, Liu L, Wang S, Tian X (2014) Adsorption of C.I. Reactive blue 19 from aqueous solutions by porous particles of the grafted chitosan. Chem Eng J 235:151-157

Kasaai MR (2007) Calculation of Mark-Houwink-Sakurada (MHS) equation viscometric constants for chitosan in any solvent-temperature system using experimental reported viscometric constants data. Carbohydr Polym 68(3):477-488

Kashif G, Saima S, Muttaqia W, Faiza A, Nik N, Mohd OAK (2016) Functionalization of magnetic chitosan with graphene oxide forremoval of cationic and anionic dyes from aqueous solution. Carbohyd Polym 152:520-531

Kumar MNVR (2000) A review of chitin and chitosan applications. React Funct Polym 46(1):1-27

Kumari S, Rath PK (2014) Extraction and characterization of chitin and chitosan from (Labeo Rohit) fish scales. Procedia Mater Sci 6:482-489

Lagergren S (1898) About the theory of so-called adsorption of soluble substances. Kungliga Svenska Vetenskapsakademiens. Handlingar 24(4):1-39

Langmuir I (1918) The adsorption of gases on the plane surfaces of glass mica and platinum. J Am Chem Soc 40:1361-1403

Liu L, Gao ZY, Su XP, Chen X, Jiang L, Yao JM (2015) Adsorption removal of dyes from single and binary solutions using a cellulose-based bioadsorbent. ACS Sustain Chem Eng 3(3):432-442

Moeinpour F, Alimoradi A, Kazemi M (2014) Efficient removal of Eriochrome black-T from aqueous solution using $\mathrm{NiFe}_{2} \mathrm{O}_{4}$ magnetic nanoparticles. J Environ Health Sci Eng 12(1):112

Mohammed MH, Williams PA, Tverezovskaya O (2013) Extraction of chitin from prawn shells and conversion to low molecular mass chitosan. Food Hydrocoll 31(2):166-171

Muzzarelli RAA, Morganti P, Morganti G et al (2007) Chitin nanofibrils/chitosan glycolate composites as wound medicaments. Carbohydr Polym 70(3):274-284

Nordine N, El Bahri Z, Sehil H, Fertout RI, Rais Z, Bengharez Z (2016) Lead removal kinetics from synthetic effluents using Algerian pine, beech and fir sawdust's: optimization and adsorption mechanism. Appl Water Sci 6:349-358

Nthunya LN, Masheane ML, Malinga SP, Nxumalo EN, Mhlanga SD (2017) Environmentally benign chitosan-based nanofibres for potential use in water treatment. Cogent Chem 3(1):1357865

Omar H, El-gendy A, Al-ahmary K (2018) Bioremoval of toxic dye by using different marine macroalgae. Turk J Bot 42(1):15-27

Pavinatto A, Pavinatto FJ, Barros-Timmons A, Oliveira ON Jr (2010) Electrostatic interactions are not sufficient to account for chitosan bioactivity. ACS Appl Mater Interfaces 2(1):246-251

Philippova OE, Korchagina EV, Volkon EV et al (2012) Aggregation of some water-soluble derivatives of chitin in aqueous solutions: role of the degree of acetylation and effect of hydrogen bond breaker. Carbohydr Polym 87(1):687-694

Rinaudo M (2006) Chitin and chitosan: properties and applications. Prog Polym Sci 31(7):603-632

Rizzi V, Longo A, Placido T et al (2018) A comprehensive investigation of dye-chitosan blended films for green chemistry applications. Inc J Appl Polym Sci 135(10):45945

Saber-Samandari S, Gulcan HO, Saber-Samandari S, Gazi M (2014) Efficient removal of anionic and cationic dyes from an aqueous solution using pullulan-graft-polyacrylamide porous hydrogel. Water Air Soil Pollut 225:2177

Sadeghi-Kiakhani M, Arami M, Gharanjig K (2013) Preparation of chitosanethyl acrylate as a biopolymer adsorbent for basic dyes removal from colored solutions. J Environ Chem Eng 1(3):406-415 
Sivakami MS, Gomathi T, Venkatesan J, Jeong HS, Kim SK, Sudha PN (2013) Preparation and characterization of nanochitosan for treatment wastewater. Int J Biol Macromol 57:204-212

Smita V, Kumar V, Abdur RQ (2017) Dye decomposition by combined ozonation and anaerobic treatment: cost effective technology. J Appl Res Technol 15(4):340-345

Tolaimate A, Desbrières J, Rhazi M, Alagui A, Vincendon M, Vottero $P(2000)$ On the influence of deacetylation process on the physicochemical characteristics of chitosan from squid chitin. Polymer 41(7):2463-2469

Tong K (2017) Preparation and biosorption evaluation of Bacillus subtilis/alginate-chitosan microcapsule. Nanotechnol Sci Appl 10:35-43

Tsaih ML, Chen RH (2003) The effect of reaction time and temperature during heterogenous alkali deacetylation on degree of deacetylation and molecular weight of resulting chitosane. J Appl Polym Sci 88:2917-2923

Uragami T, Tanaka Y, Nishida S (2002) Permeation and separation under high temperature and high pressure for ethanol/water vapors through cross-linked quaternized chitosan composite membranes. Desalination 147(1):449-454

Vaz MG, Pereira AGB, Fajardo AR, Azevedo ACN, Rodrigues FHA (2017) Methylene blue adsorption on chitosan-g-poly(acrylic acid)/rice husk ash superabsorbent composite: kinetics, equilibrium, and thermodynamics. Water Air Soil Pollut 228:14

Vega-Negron AL, Alamo-Nole L, Perales-Perez O, Gonzalez-Mederos AM, Jusino-Olivencia C, Roman-Velazquez FR (2018) Simultaneous adsorption of cationic and anionic dyes by chitosan/cellulose beads for wastewaters treatment. Int J Environ Res 12(1):59-65

Wang QZ, Chen XG, Liu N, Wang SX, Liu CS, Meng XH, Liu CG (2006) Protonation constants of chitosan with different molecular weight and degree of Deacetylation. Carbohydr Polym 65:194-201

Wang Y, Wang W, Wang A (2013) Efficient adsorption of methylene blue on an alginate-based nanocomposite hydrogel enhanced by organo-illite/smectite clay. Chem Eng J 228:132-139
Xie J, Li C, Chi L, Wu D (2013) Chitosan modified zeolite as a versatile adsorbent for the removal of different pollutants from water. Fuel 103:480-485

Xin X, Si W, Yao Z, Feng R, Du B, Yan L, Wei Q (2011) Adsorption of benzoic acid from aqueous solution by three kinds of modified bentonites. J Colloid Interface Sci 359:499-504

Yagub MT, Sen TK, Afroze S, Ang HM (2014) Dye and its removal from aqueous solution by adsorption: a review. Adv Colloid Interface Sci 209:172-184

Yen MT, Yang JH, Mau JL (2009) Physicochemical characterization of chitin and chitosan from crab shells. Carbohydr Polym 75(1):15-21

Younes I, Ghorbel-Bellaaj O, Chaabouni M et al (2014) Use of a fractional factorial design to study the effects of experimental factors on the chitin Deacetylation. Int J Biol Macromol 70:385-390

Yuan Y, Chesnutt BM, Haggard WO, Bumgardner JD (2011) Deacetylation of chitosan: material characterization and in vitro evaluation via albumin adsorption and pre-osteoblastic cell cultures. Materials 4(8):1399-1416

Yun Yang B, Montgomery R (1999) Degree of acetylation of heteropolysaccharides. Carbohydr Res 323:156-162

Zubair M, Jarrah N, Manzar MS, Al-Harthi M, Daud M, Mu'azu ND, Haladu SA (2017) Adsorption of Eriochrome black T from aqueous phase on $\mathrm{MgAl}-$, CoAl- and NiFe-calcined layered double hydroxides: kinetic, equilibrium and thermodynamic studies. J Mol Liq 230:344-352

Publisher's Note Springer Nature remains neutral with regard to jurisdictional claims in published maps and institutional affiliations. 